\title{
Life-threatening, localized angio-oedema associated with streptokinase
}

\author{
John P. Cooper, Daniel P. Quarry'1, Derek J. Beale' ${ }^{1}$ and A. Guy Chappell ${ }^{1}$ \\ Department of Cardiology, The Middlesex Hospital, Mortimer Street, London WIN 8AA and ${ }^{1}$ Princess of \\ Wales Hospital, Coity Road, Bridgend, Mid Glamorgan, CF31 IRQ, UK
}

Summary: We report what we believe to be the first documented case of localized angio-oedema of the upper airway secondary to streptokinase.

\section{Introduction}

Streptokinase is now routinely used in the treatment of acute myocardial infarction as it is relatively cheap and as effective as other thrombolytic agents in improving mortality. Allergic reactions to streptokinase rarely occur but as described here may be life threatening and unrelated to previous exposure.

\section{Case report}

A 59 year old woman was admitted to hospital with severe chest pain subsequently confirmed to be due to myocardial infarction. She suffered from stable angina and maturity onset diabetes and had sustained an anterior myocardial infarction 2 years prior to the admission for which she was not given thrombolytic therapy. She had no history of a recent sore throat or allergies and was taking daily propanolol $60 \mathrm{mg}$, aspirin $150 \mathrm{mg}$, isosorbide mononitrate $30 \mathrm{mg}$, frusemide $40 \mathrm{mg}$ and gliclazide $320 \mathrm{mg}$. Eight hours after the onset of her pain she was commenced on an intravenous infusion of 1.5 million units of streptokinase in 5\% dextrose over one hour.

Ten minutes later, after receiving approximately 0.2 million units, she complained of periorbital swelling. The infusion was stopped immediately, and she was given $100 \mathrm{mg}$ hydrocortisone and $4 \mathrm{mg}$ chlorpheniramine intravenously. She remained normotensive with a pulse rate of 60 beats/ minute and there was no rash or fever. An emergency clotting screen confirmed significant amounts of streptokinase had been received (prothrombin time 25, control 15 seconds; activated partial thromboplantin time 60 , control 28 seconds; thrombin time $>200$, control 14 seconds; fibrinogen

Correspondence: J.P. Cooper, B.Sc., M.R.C.P., M.D. Accepted: 3 December 1993
0.4 , control $>1.5 \mathrm{~g} / \mathrm{ml}$ ). Over the next 5 minutes she complained of choking as her tongue and lips swelled. Within a further 5 minutes she was unable to talk as her tongue was grossly oedematous, protruding from her mouth. She had no stridor and her oxygen saturation on $55 \%$ oxygen was $98-99 \%$. In view of her deteriorating condition, $1 \mathrm{ml}$ of $1: 10,000$ adrenaline was injected slowly intra venously. Five minutes later there was no obvious improvement in her condition and so the injection was repeated. Five minutes after this she developed ventricular tachycardia at a rate of 200 beats/ minute, lost consciousness and had an epileptic fit. She was immediately cardioverted to sinus rhythm with a $200 \mathrm{~J}$ shock and given a $100 \mathrm{mg}$ bolus of intravenous lignocaine and $5 \mathrm{mg}$ diazepam. She regained consciousness and over the next 30 minutes the periorbital and tongue oedema subsided until after 4 hours the oedema was no longer present. Her blood pressure was well maintained throughout this period. She subsequently made an uneventful recovery.

\section{Discussion}

The incidence of allergic reactions to streptokinase in the large thrombolytic trials varies between $1.7 \%{ }^{1}$ and $4.4 \%{ }^{2}$ whilst life-threatening reactions varies between $0 \%{ }^{1,2}$ and $0.1 \% .^{3}$ These are usually anaphylactic reactions manifest by rashes, hypotension, tachycardia and cardiopulmonary arrest. ${ }^{4}$ Although urticaria has been reported as part of anaphylaxis to streptokinase, ${ }^{5}$ ours is the first published report to our knowledge and the first received by the Committee on Safety of Medicines of angio-oedema of the airway occurring in the absence of urticaria or other signs of anaphylaxis (Committee on Safety of Medicines, personal communication). 
The conventional treatment for life-threatening angio-oedema includes hydrocortisone and chlorpheniramine given intravenously and $1 \mathrm{ml} 1: 1,000$ adrenaline given subcutaneously. We considered the patient's condition to be deteriorating so rapidly to warrant treatment with intravenous adrenaline given slowly. The initial dose given is $1 / 10$ th of the initial intravenous bolus dose recommended for patients who have undergone an asystolic cardiac arrest and is near the maximum dose a patient should receive every 5 minutes if on a constant infusion of intravenous adrenaline.

Angio-oedema involving the airway is a lifethreatening condition which may require an emergency tracheostomy or mini-tracheostomy, a

\section{References}

1. Gruppo Italiano per lo Studio della Sopravvivenza nell'Infarto Miocardico. GISSI-2: a factorial randomised trial of alteplase versus streptokinase and heparin versus no heparin among 12,490 patients with acute myocardial infarction. Lancet 1990 , 336: 65-75.

2. Second International Study of Infarct Survival (ISIS-2). Randomised trial of intravenous streptokinase, oral aspirin, both, or neither among 17,187 cases of suspected acute myocardial infarction. ISIS-2. Lancet 1988, ii: 349-360.

3. Gruppo Italiano per lo Studio della Streptochinasi nell'Infarto Miocardico (GISSI). Effectiveness of intravenous thrombolytic therapy in acute myocardial infarction. Lancet 1986, i: $397-401$. dangerous procedure whilst the clotting system is deranged following thrombolysis. The results of the largest study comparing thrombolytic agents, ISIS- $3,{ }^{6}$ suggest that streptokinase in preference to tPA (tissue plasminogen activator) should be used in patients presenting with acute myocardial infarction who have not previously been exposed to streptokinase, on the grounds that both agents are equally effective in reducing mortality, and that streptokinase is cheaper and has a lower incidence of cerebral bleeding. However, this case demonstrates that absence of previous exposure to streptokinase does not preclude the occurrence of rare life-threatening allergic reactions.

4. Bednarczyk, E.M., Sherlock, S.C., Farah, M.G. \& Green, J.A. Anaphylactic reaction to streptokinase with first exposure: case report and review of the literature. DICP. The Annals of Pharmacotherapy 1989, 23: 869-872.

5. McGrath, K.K. \& Patterson, R. Anaphylactoid reactivity to streptokinase. JAMA 1984, 252: 1314-1317.

6. ISIS-3. A randomised comparison of streptokinase vs tissue plasminogen activator vs antistreplase and of aspirin plus heparin vs aspirin alone among 41,299 cases of suspected acute myocardial infarction. Third International Study of Infarct Survival Collaborative Group. Lancet 1992, 339: 753-770. 